Article

\title{
Preparation of $n$-Alkane/Polycaprolactone Phase-Change Microcapsules via Single Nozzle Electro-Spraying: Characterization on Their Formation, Structures and Properties
}

\author{
Shengchang Zhang, Christine Campagne and Fabien Salaün *(D) \\ ENSAIT, GEMTEX-Laboratoire de Génie et Matériaux Textiles, F-59000 Lille, France; \\ shengchang.zhang@ensait.fr (S.Z.); christine.campagne@ensait.fr (C.C.) \\ * Correspondence: fabien.salaun@ensait.fr; Tel.: +33-(0)-320-25-64-59
}

Received: 5 December 2019; Accepted: 9 January 2020; Published: 13 January 2020

\begin{abstract}
The phase change microcapsule ( $\mathrm{mPCM}$ ) is one of the primary candidates in the fields of energy storage and thermal regulation. In this study, electro-spraying, as a green, high-efficiency electrohydrodynamic atomization technology, is applied to the microencapsulation of two phase change materials (PCM) ( $n$-hexadecane and $n$-eicosane) with three loading contents $(30 \%, 50 \%$, and $70 \%$ by weight) in a polycaprolactone matrix. Ethyl acetate (EA) and chloroform (Chl) were chosen as solvents to prepare the working solutions. The objective of this study is to clarify the microencapsulation process during electro-spraying and to optimize the structure and properties of the electro-sprayed mPCM. The structures, morphologies, and thermal properties of the MPCM were characterized by optical microscopy (OM), scanning electron microscopy (SEM), differential scanning calorimeter (DSC), thermogravimetric analysis (TGA), and fourier transform infrared spectroscopy (FT-IR). Electro-sprayed spherical and non-porous MPCM have been successfully prepared. The mean diameter and the particle size distribution depend mainly on the choice of the $n$-alkane, as well as the solvent used to prepare the working solutions. Meanwhile, the structure formation of electro-sprayed $\mathrm{mPCM}$ and the loading content of PCM were mainly influenced by the evaporation of the solvent and the phase separation between PCM and poly(caprolactone) (PCL) matrix. During the shell formation or PCL solidification, the control of the PCM leaching out of the matrix allows improving the loading content. Finally, based on a high latent heat and simple formation process, the electro-spraying route of PCM is a green, non-toxic, and high-efficiency direction for energy storage and heat regulation.
\end{abstract}

Keywords: phase-change microcapsules; electrospraying; poly(caprolactone); paraffin wax; formation mechanism; structure and morphology; thermal properties

\section{Introduction}

Phase change materials (PCM) are inorganic or organic compounds, which can store or release a large amount of latent heat during their phase change transition induced with the surrounding temperature variations [1-5]. Thus, they are mainly used in space applications, smart textile structures, battery thermal management, industrial waste heat recovery, building energy conservation, and solar energy, in order to manage the thermal management due to their high energy storage density [6-9]. The use of organic phase change materials has some limitations due to their low thermal conductivity, low density, high volatilization, and flammability $[10,11]$. Since they are sometimes in their liquid phase, they cannot be applied on a substrate without being stabilized, which overcomes their drawbacks [12-16]. The PCM shape stabilization technique is one of the well-known ways to achieve the best benefits in energy storage in practical applications [17]. The PCM shape stabilizing materials can be obtained from 
various routes. Their microencapsulation improves heat transfer by increasing the surface-to-volume ratio [18]. Their incorporation into a polymer matrix is a low-cost technology. The use of nanomaterials in composite design improves their stability [19], while their impregnation into porous materials prevents their leakage, as well as the formulation of solid-solid phase change materials.

The encapsulation step leads, not only to protect the active substance and to prevent leaching, but also to an increase in the specific surface contact area, and therefore, improve the thermal transfer management. Microencapsulation of PCM is mainly carried out via in-situ polymerization [18], interfacial polycondensation [20], sol-gel method [21,22], simple or complex coacervation [23,24], phase separation or suspension process [25,26], and spray drying [27-29]. These methods have some drawbacks in the preparation of phase-change microcapsules, such as the complex shell formation process, the use of toxic substances or organic solvent, chemical additives and surfactants, and the difficulty in the control of structure, as well as morphology (i.e., size, shape, and porosity). Electrospraying method, as a one-step electrohydrodynamic atomization technology, has great potential and advantages to fabricate polymeric microcapsules or nanocapsules in a green and simple way [30-33]. Furthermore, the control of the process and formulation parameters avoids particle aggregation and ensures a narrow and mono-dispersed particle size distribution under stable cone-jet mode. It also ensures the the shape, the surface state and porosity, and phase structure of microcapsules to be adjusted [34,35].

Among the electrohydrodynamic atomization technologies, the electrospinning method is the most used with the phase change materials to prepare core-sheath structure nanofibers from a coaxial system [36-38]. The use of electrospraying for PCM microencapsulation, even if some authors recognize it as a suitable method, is seldom described in the scientific literature [39]. In their works, Moghaddam et al. prepared $n$-nonadecane/sodium alginate $\mathrm{mPCM}$, using melting coaxial electrospraying [39-41]. The formation of the shell was carried out via the cross-linking solidification reaction between alginate solution (outer liquid) and calcium chloride in collecting bath. The investigation of the alginate solution concentration and the optimization of the process parameters, controlling the mean diameter of the particles, allowed them to reach an encapsulation efficiency of about $59 \%$, a phase change enthalpy of their capsules about $88 \mathrm{~J} / \mathrm{g}$, and a mean diameter between 200 to $700 \mu \mathrm{m}$. $\mathrm{N}$-octadecane was successfully entrapped in a polyamic acid shell via a coaxial electrospraying process [42]. The authors observed that the core feed rate affected the surface morphology as well as the mean diameter of the capsules. Furthermore, microcapsules with a mean diameter between 1 to 2 $\mu \mathrm{m}$, with narrow size distribution and a loading content of $60 \%$, were obtained.

In single nozzle electrospraying, a solvent able to solubilize both polymer shell and PCM is used to form the working solution. Then, this solution is pumped out from the electro-sprayed nozzle with an applied voltage to prepare mPCM. During the evaporation of the solvent, the solvent's richest phase diffuses to form a shell, and poor solvent phase stays in the inner part of the microcapsules to form the core, due to the solubility differences between matrix and PCM in the working solvent. The cone-jet mode is challenging to reach when compounds with low electrical conductivity, such as PCM, are used. Therefore, the use of a suitable solvent was required to be solubilized and improve its electro-sprayability. Thus, the formation and the final properties of electro-sprayed MPCM particles are not only determined by the feed ratio between the polymeric shelling the core, but also by the breakup of electro-sprayed droplets, the evaporation of solvent, the diffusion of PCM and the phase separation, to lead the formation of the shell around the PCM during the electrospraying process. Until now, there is no publication to investigate the effects of these processes mentioned later on the structure characteristics (mean diameter, morphology, and loading content of PCM) and thermal properties of the electrosprayed mPCM.

In this work, the design of PCM microencapsulation from a single nozzle electrospraying process, based on the entrapment of PCM-loaded microparticles in a polyester matrix or shell was proposed, and its impact on the resulting thermal properties was assessed. $N$-hexadecane and $n$-eicosane have been selected as liquid and solid PCMs at room temperature, ethyl acetate (EA), and chloroform (Chl) 
as solvents for the working solutions, and polycaprolactone (PCL) as shell material. The loading content, as well as the encapsulation efficiency, were also investigated according to the core/shell ratio. The structures, morphologies, and properties of electro-sprayed MPCM were characterized by optical and scanning electron microscopies (OM and SEM), the chemical structure of the obtained microparticles were assessed by Fourier transform infrared spectroscopy (FT-IR), and the thermal properties by differential scanning calorimetry (DSC) and thermogravimetric analysis (TGA).

\section{Materials and Methods}

\subsection{Materials}

Polycaprolactone (PCL), used as matrix or shell polymer (CapaTM 6400, mean molecular weight 37,000 $\mathrm{g} \cdot \mathrm{mol}^{-1}$ ) was purchased from Perstorp (Malmö, Skåne County, Sweden). Ethyl acetate (EA) and chloroform (Chl) were purchased from Sigma Aldrich (Dorset, UK). $N$-hexadecane $\left(\mathrm{C}_{16}\right.$-parafol 16-97) and $n$-eicosane $\left(\mathrm{C}_{20}\right.$-parafol $\left.20 \mathrm{z}\right)$ were obtained from Sasol Germany Gmbh (Hamburg, Germany). All reagents were used as received without any further treatment.

\subsection{Preparation of PCM/PCL Electrospraying Solutions}

A series of PCM/PCL electrospraying solutions with different weight ratios, PCM to PCL, were prepared from the solubilization of PCL in ethyl acetate or chloroform $(10 \mathrm{wt} . \%)$ at $40{ }^{\circ} \mathrm{C}$ under vigorous magnetic stirring during $1 \mathrm{~h}$. The required weight of PCM was subsequently added to achieve final PCM/PCL weight ratios of 0/100, 30/70, 50/50, and 70/30, under continuous agitation during $2 \mathrm{~h}$.

\subsection{Production of Microencapsulation Structures by Electrospraying}

The previous formulations were processed using a CAT000002 Electrospraying Starter Kits purchased from Spraybase ${ }^{\circledR}$ AVECATS (Kildare, Ireland). The solutions were pumped with a digitally controlled syringe pump at a flow-rate of $1 \mathrm{~mL} / \mathrm{h}$ through a single stainless steel nozzle (26 gauge, single nozzle, outer diameter: $460 \mu \mathrm{m}$, inner diameter: $260 \mu \mathrm{m}$ ). The applied voltage between nozzle and collector was set $4.0 \mathrm{kV}$. Samples were collected on a grounded copper plate covered with aluminum foil for SEM analyses, with glass slides for OM analyses and metal dish for the other characterizations, with a collecting time of 10,3, and $300 \mathrm{~min}$, respectively. All the containers were placed at $17 \mathrm{~cm}$ from the tip of the nozzle, and during the various experiments, temperature and relative humidity were kept constant at $25{ }^{\circ} \mathrm{C}$, and $45 \%$, respectively.

\subsection{Morphological Characterization of the Particles}

Scanning electron microscopy was conducted on an Inspect F50 (FEI Company, Hillsboro, OR, USA) at an accelerating voltage of $20 \mathrm{kV}$. The microparticles samples were coated with gold before analysis. Electro-sprayed phase-change microparticles were observed via optical microscopy (Motic BA410, Barcelona, Spain) coupled to a Moticam 5 Digital Camera (Barcelona, Spain), controlled by the software Motic image plus 3.0 which was used to analyze the microparticles. Particles diameters were measured from the OM and SEM micrographs using the Image J software. Size distributions were obtained from a minimum of 200 random measurements. The obtained data were statistically analyzed in a spreadsheet (Microsoft Excel 2011, Microsoft Company, Redmond, WA, USA) to calculate the mean diameter as well as the particle size distribution.

\subsection{Fourier Transform Infrared (FT-IR) Analysis of the Samples}

The chemical structure of electro-sprayed mPCM was analyzed by Fourier transform infrared spectroscopy (Nexus-560 spectrometer, Nicolet, Madison, WI, USA). The powdery electro-sprayed materials were dispersed in spectroscopic grade potassium bromide $(\mathrm{KBr})$, and analyzed in absorbance mode. All spectra were acquired in the wavenumber range of $400-4000 \mathrm{~cm}^{-1}$, by averaging 256 scans at $2 \mathrm{~cm}^{-1}$ resolution. 


\subsection{Thermal Analyses of the Samples}

The thermal behavior of $n$-hexadecane, $n$-eicosane, PCL microparticles and mPCM was recorded using a DSC 3+ (Mettler Toledo, Columbus, OH, USA) piloted on PC with STARe software. The sample space was purged with nitrogen flow during the experiments. The onset temperatures of solid-liquid and liquid-solid transitions ( $\left.T_{\text {onset }}\right)$, end temperatures of phase transitions $\left(T_{\text {end }}\right)$, and maximum temperatures of melting $\left(T_{m}\right)$ and crystallization $\left(T_{c}\right)$, as well as melting $\left(\Delta H_{m}\right)$ and crystallization $\left(\Delta H_{C}\right)$ enthalpies of each transitions were determined. 3-8 $\mathrm{mg}$ of microcapsules (or $n$-alkanes) were placed in an aluminum pan and placed in DSC apparatus, heated from $-20^{\circ} \mathrm{C}$ to $80^{\circ} \mathrm{C}$ at $5{ }^{\circ} \mathrm{C} \cdot \mathrm{min}^{-1}$, held constant at $80^{\circ} \mathrm{C}$ for $10 \mathrm{~min}$, and then cooled to $-20^{\circ} \mathrm{C}$ at the same scanning rate, and held for $10 \mathrm{~min}$. Each test was conducted twice' and carried out with a least three independent experiments. Values were taken on every second cycle. On the base of phase transitions enthalpies, the loading content (LC) as well as the encapsulation efficiency (EE) were calculated from the Equations (1) and (2) [43],

$$
\begin{gathered}
L C=\frac{\Delta H_{m P C M}}{\Delta H_{P C M}} \\
E E=\frac{L C}{L C_{t h}}
\end{gathered}
$$

where, $\triangle H_{m P C M}$ and $\triangle H_{P C M}$ are the melting enthalpies of microparticles, and $n$-alkanes (n-hexadecane $\sim 199 \mathrm{~J} \cdot \mathrm{g}^{-1}$, and $n$-eicosane $\sim 205 \mathrm{~J} \cdot \mathrm{g}^{-1}$ ), respectively. $L C_{t h}$ is the theoretical loading content.

The relative crystallinity of the PCL matrix in the samples $\left(X_{\mathcal{c}}\right)$ was calculated according to Equations (3) and (4),

$$
\begin{aligned}
& X_{\mathcal{C}(m)}=\frac{\Delta H_{m(\text { PCL phase in } m P C M)}}{\Delta H_{m(P C L)}^{0}\left(1-w_{m(m)}\right)} \times 100 \\
& X_{c(t h)}=\frac{\Delta H_{m(P C L \text { phase in } m P C M)}}{\Delta H_{m(P C L)}^{0}\left(1-w_{m(t h)}\right)} \times 100
\end{aligned}
$$

where, $\Delta H_{m}$ is the specific melting heat, $\Delta H_{m}^{0}$ is the theoretical specific heat of $100 \%$ crystalline PCL, which was taken as $139.5 \mathrm{~J} \cdot \mathrm{g}^{-1}$ [44], and $w_{m}$ was the weight fraction of PCM in the samples.

The thermal stability of $n$-alkanes, PCL microparticles and $\mathrm{MPCM}$ were assessed by thermogravimetric analysis, carried out on a TGA 3+ (Mettler Toledo, Columbus, OH, USA) under inert atmosphere at a purge rate of $50 \mathrm{~mL} \cdot \mathrm{min}^{-1}$. A heating rate of $10{ }^{\circ} \mathrm{C} \cdot \mathrm{min}^{-1}$ was applied, and the temperature raised from 20 to $700{ }^{\circ} \mathrm{C}$. For each experiment, 3 to $8 \mathrm{mg}$ was used in the TGA test. In addition to the percentage weight (TG) curves, the derivative weight loss percentage (DTG) was calculated for each sample.

\section{Results and Discussion}

\subsection{Size and Morphology of Electro-Sprayed $m P C M$}

The size, the surface state, and the morphology of electro-sprayed MPCM were characterized by SEM and OM observations (Figure 1). They are mainly influenced by the PCM content, the phase change temperature of the PCMs used during the process, and also the choice of the solvents. Blank PCL particles present a spherical shape, whatever the solvent selected to solubilize PCL, i.e., chloroform or ethyl acetate (Figure 1(n1,n2)). The use of chloroform allows the particles to have a smooth surface state. In contrast, the solubilization in ethyl acetate solution leads to the formation of a single-pore morphology as previously described by Zhang et al. [45]. Adding PCMs in the working solution does not have a substantial effect on the obtained morphology, since the obtained particles are also spherical. Nevertheless, the increase of $n$-alkanes in the solution leads to an increase in the mean diameter and the particle size distribution. Furthermore, in the case of the use of EA as the solvent, single-pore morphology turns to a non-porous morphology for PCM/PCL blends. 


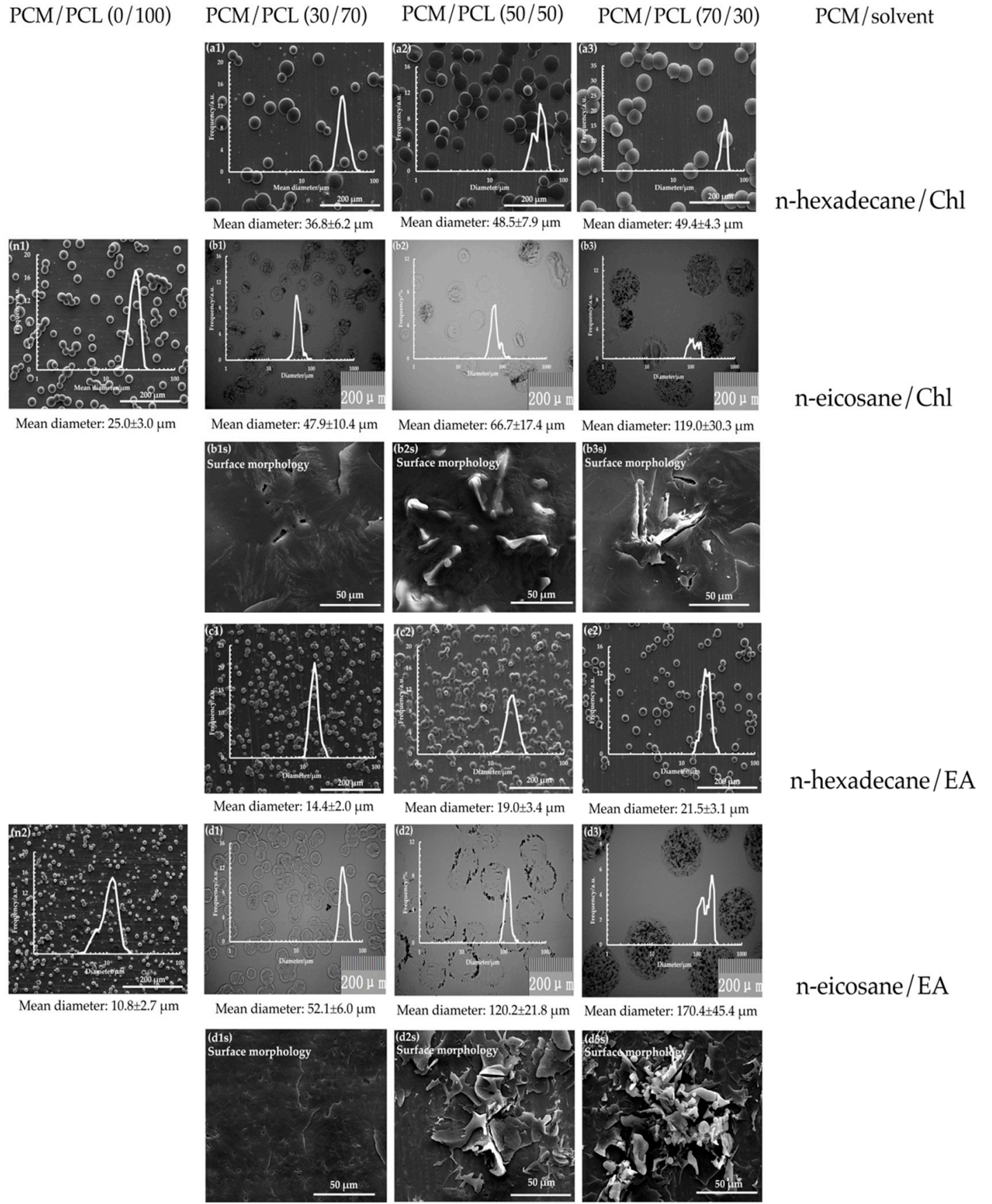

Figure 1. Scanning electron microscopy (SEM) and optical microscopy (OM) graphs of neat poly(caprolactone) (PCL) microspheres and mPCM obtained from different conditions (n1) neat PCL microspheres obtained from chloroform (n2) neat PCL microspheres obtained from ethyl acetate (a1-a3) n-hexadecane/PCL/chloroform microcapsules (b1-b3) n-eicosane/PCL/chloroform microcapsules (b1s-b3s: Their surface morphologies) (c1-c3) n-hexadecane/PCL/ethyl acetate microcapsules (d1-d3) n-eicosane/PCL/ethyl acetate microcapsules (d1s-d3s: their surface morphologies) (scale bar: $200 \mu \mathrm{m}$ ) (b1s-b3s and d1s-d3s) the magnification SEM images of related sample surface morphology (scale bar: $50 \mu \mathrm{m})$.

The use of $n$-hexadecane and $n$-eicosane does not lead to the same granulometric properties, even if their molecular chain length differs by four carbon atoms. $N$-hexadecane is in its liquid state at room temperature, while $n$-eicosane is in its solid state. Under the action of Coulombic repulsions, the break-up process of $n$-eicosane/PCL charged droplets is different from that of $n$-hexadecane/PCL 
one. During the flying process, from the nozzle to the collector, droplets containing $n$-eicosane start their solidification at the earliest stages due to the evaporation of the solvent, which induces an enhancement of $n$-eicosane chain interactions and, therefore, their crystallization. Therefore, it leads to a higher specific surface to volume ratio, which prevents the further break-up process of the electro-sprayed droplets, unlike $n$-hexadecane, which is in a liquid state throughout the process. Furthermore, the crystallization being an exothermic phenomenon increases the local temperature in the inner core of the droplets, which leads to a growth of the solvent evaporation rate. Therefore, the use of $n$-eicosane leads to the formation of particles having a higher mean diameter and particle size distribution than with $n$-hexadecane one. Since solid particles are obtained in the earliest stages of the flying process, in the last steps, the solvent release results in the obtaining of the rough and wrinkled surface state of the particles, which is more pronounced with the increase of $n$-eicosane content. Thus, the black color observed in OM micrographs of $n$-eicosane/PCL particles belonged to $n$-eicosane laying on the surface of the PCL matrix (Figure 1(b3,d3)). At low content in $n$-eicosane, the core compound is completely entrapped by the PCL shell, but when it increased due to the thermodynamical phenomena and solvent evaporation, it diffuses on the surface of the particles.

The granulometric properties of the electro-sprayed particles, as well as their morphology, are also affected by the solvent choice, that is used to solubilize the polymer and the $n$-alkane. Thus, in the presence of ethyl acetate (Figure 1(c1-c3)), the obtained particles with $n$-hexadecane have a lower mean diameter and a narrower size distribution than with chloroform (Figure 1(a1-a3)). This is related to the higher vapor pressure solution and viscosity of the chloroform based solution [45]. During the earliest stages of the flying process, chloroform evaporates quicker in the surrounding medium compared to ethyl acetate solution, and in the absence or at low solvent content, the process break-up stops before to reach the collector. Furthermore, high viscosity also depresses the break-up process of the charged droplets, resulting in a higher size of the electro-sprayed particles [46].

On the other hand, the mean diameter and the particle size distribution of the electro-sprayed $n$-eicosane particles are determined in the earliest stage of the process due to core compound crystallization, which allows solid particles to be obtained. Then, in the presence of chloroform (Figure 1(b1-b3)), the process break-up coupled to the solvent evaporation allows the formation of tinier particles than with ethyl acetate (Figure 1(d1-d3)) since more solvent is released.

Also, the crystallization of $n$-eicosane plays a primary role in the obtained morphology. Thus, $n$-eicosane/PCL microcapsules, obtained from ethyl acetate, are rougher and more wrinkled than those obtained from chloroform (Figure 1(b1s-b3s) and Figure 1(d1s-d3s)). During the solidification of the $n$-alkane, ethyl acetate gradually is released from these particles until reaching the collector, which allows the diffusion of the $n$-alkanes chains to the surface of the particles. Whereas, in the presence of chloroform, due to its quick evaporation, $n$-eicosane is located in the inner core of the particles.

\subsection{Structure of Electro-Sprayed $m P C M$}

FT-IR spectra of PCL microparticles, $n$-hexadecane/PCL microparticles in EA (30/70, 50/50; 70/30), $n$-hexadecane/PCL microparticles in Chl, and $n$-eicosane/PCL microparticles in Chl are depicted in Figure 2. PCL microparticles spectrum shows a strong absorption band at $1750 \mathrm{~cm}^{-1}$ corresponding to the stretching vibration of carbonyl group, and characteristic bands at 2915 to $2860 \mathrm{~cm}^{-1}$ associated with the aliphatic $\mathrm{C}-\mathrm{H}$ stretching vibrations. The characteristic bands at $1475 \mathrm{~cm}^{-1}, 1397 \mathrm{~cm}^{-1}$, and $1361 \mathrm{~cm}^{-1}$ are attributed to the bending vibration of the alkyl group, and those located at $1230 \mathrm{~cm}^{-1}, 1107 \mathrm{~cm}^{-1}$, and $1042 \mathrm{~cm}^{-1}$ corresponding to the stretching vibration of -CO-C- group. Stretching vibrations of -C-C- and -CO- are found at 1290, and $1160 \mathrm{~cm}^{-1}$, respectively [47]. PCM spectra exhibit a strong absorption band at $2920-2852 \mathrm{~cm}^{-1}$ associated with the aliphatic $\mathrm{C}-\mathrm{H}$ stretching vibrations of the $n$-hexadecane or $n$-eicosane. The in-plane rocking vibration of the $\mathrm{CH}_{2}$ groups is observed at $717 \mathrm{~cm}^{-1}$, and $\mathrm{C}-\mathrm{H}$ bending vibration in $\mathrm{CH}_{2}$ is found at 1470 and $1370 \mathrm{~cm}^{-1}$. All of the characteristic peaks for $n$-hexadecane, or $n$-eicosane, and PCL, are clearly distinguished in the spectra of the FT-IR spectra of 
the electro-sprayed micro-particle samples, which verifies that $n$-alkane are successfully entrapped by PCL.

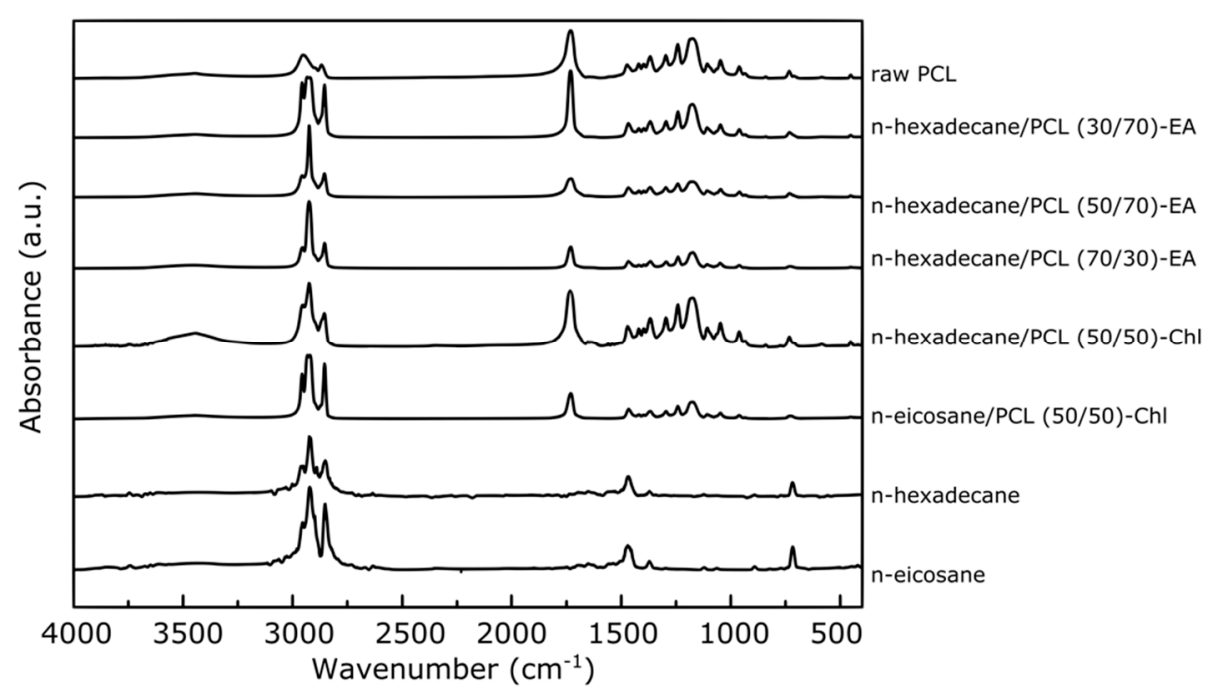

Figure 2. The fourier transform infrared spectroscopy (FT-IR) spectra of $n$-eicosane, $n$-hexadecane, neat PCL microsphere and a series of $\mathrm{MPCM}$ obtained from different conditions.

\subsection{Phase Change Properties of Electro-Sprayed mPCM}

The phase change temperatures and the latent heats of melting and crystallization of raw $n$-alkanes, neat PCL microspheres, and MPCM were obtained using differential scanning calorimeter. They are presented in Figures 3 and 4, and gathered in Tables 1 and 2. On the one hand, the latent heats of fusion of raw $n$-hexadecane and $n$-eicosane are 199 , and $205 \mathrm{~J} \cdot \mathrm{g}^{-1}$, respectively. Their melting and crystallization temperatures are found at $17.9^{\circ} \mathrm{C}, 16.2^{\circ} \mathrm{C}, 34.3^{\circ} \mathrm{C}$, and $35.7{ }^{\circ} \mathrm{C}$. On the other hand, the onset of melting and crystallization temperatures of PCL microspheres are determined at 54.9 and $41.2{ }^{\circ} \mathrm{C}$, when they have been prepared from ethyl acetate solution, and 55.6 and $41.5^{\circ} \mathrm{C}$ from chloroform. The solvent used modifies to a limited extent the crystallinity since it is about $40.8 \%$ and $42.7 \%$ for the samples prepared from EA, and Chl, respectively. DSC thermograms of microencapsulated PCM have both the thermal transitions of the $n$-alkanes used and PCL.
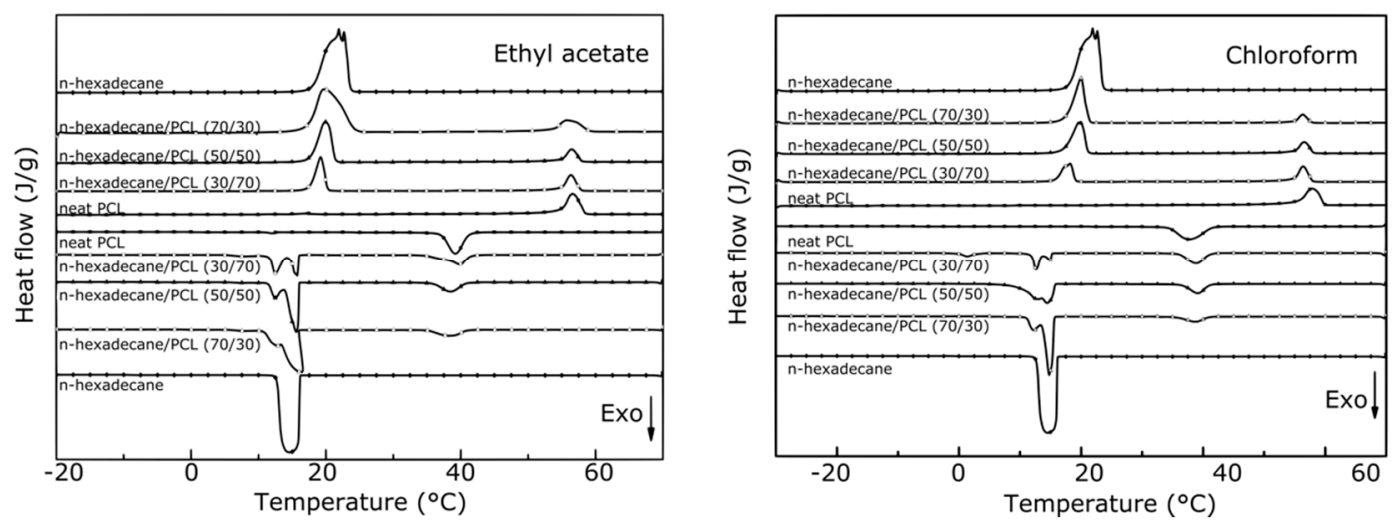

Figure 3. DSC cuves of $n$-hexadecane, neat PCL microspheres and a series of $n$-hexadecane/PCL microcapsules obtained from different solvents with different mass ratios between $n$-hexadecane and PCL. 

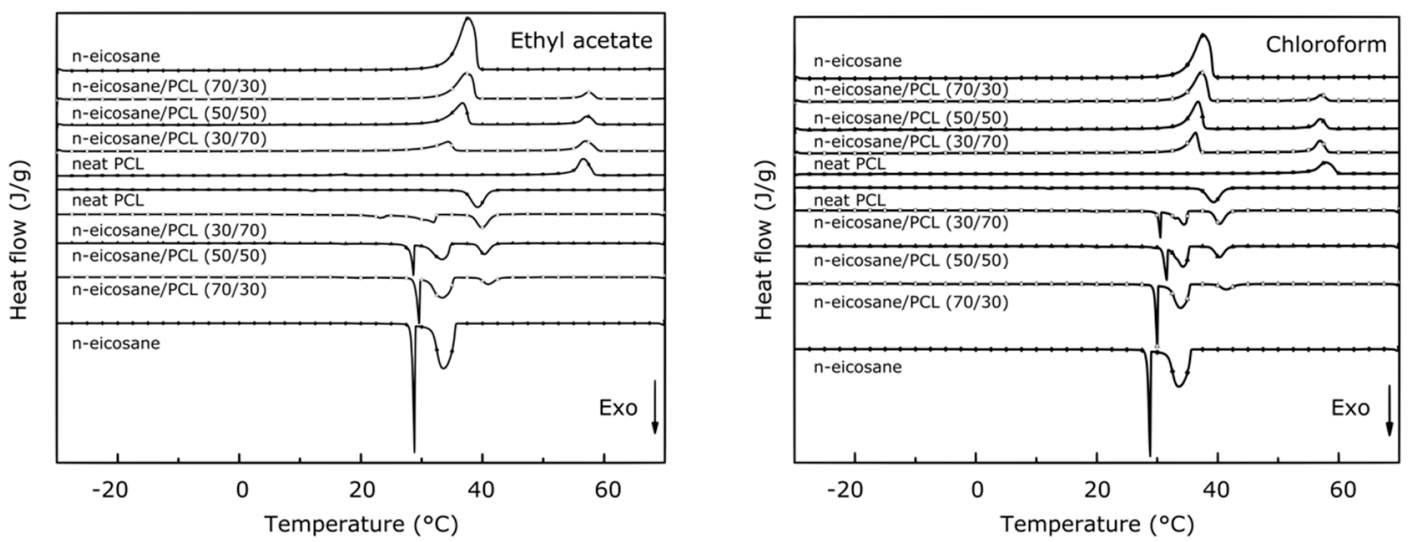

Figure 4. Differential scanning calorimeter (DSC) cuves of $n$-eicosane, neat PCL microspheres and a series of $n$-eicosane/PCL microcapsules obtained from different solvents with different mass ratios between $n$-eicosane and PCL.

The increase of $n$-hexadecane to PCL from 30 to $70 \mathrm{wt} . \%$ in the EA working solution results in the increase of the melting (and crystallization) enthalpy from 52 to $113 \mathrm{~J} \cdot \mathrm{g}^{-1}$, corresponding to an increase of the loading content from 26 to $56 \%$, which is a quite lower than the theoretical content. On the other hand, the encapsulation efficiency reaches a maximum of $89 \%$ for $50 \mathrm{wt} . \%$, then decreases to $81 \%$ for $70 \mathrm{wt} . \%$. The loading content does not have a significant effect on the phase change transition temperatures, which are close to the raw $n$-hexadecane one. The mPCM obtained from chloroform solution have lower melting enthalpy than those with ethyl acetate. The encapsulation efficiency is slightly lower too. Furthermore, the melting and crystallization temperatures for low loading content are found relatively lower compared to the other content. The loss of $n$-hexadecane during electrospray microencapsulation results from the evaporation of the solvent in flight, which promotes phase separation between $n$-hexadecane and PCL, and sometimes the presence of pure tiny droplet of $n$-hexadecane. The rigidification of the PCL hindrances this phenomenon. $n$-hexadecane is highly soluble in chloroform than in ethyl acetate, and therefore, has a better compatibility $[48,49]$. Thus, the use of the chloroform working solution induces a higher loss in $n$-hexadecane during its evaporation. The use of ethyl acetate may prevent this phenomenon, and therefore, higher loading content in PCM in the microcapsules, are reached.

Apart from $n$-hexadecane/PCL microcapsules, the thermal properties of $n$-eicosane-based mPCM, obtained from different solvents and various weight ratios between the $n$-alkane and PCL, are also presented in Figure 4 and Table 2. On the one hand, the presence of the PCL and the choice of the solvent used for the working solution does not affect the phase temperatures, which are quite similar to the raw $n$-hexadecane one. On the other hand, the use of chloroform allows entrapping higher content of $n$-eicosane (more than 10\%) compared to the use of ethyl acetate. These results are the opposite of those obtained in the case of $n$-hexadecane, highlighting the influence or importance of the phase change that takes place during the process. Thus, the solvent evaporation, which occurs in the early stages of the electro-spraying process, induces a fast phase separation and further the PCM crystallization, which also promotes the stiffening of the PCL. In this context, the more volatile the solvent of the working solution, the more PCM is entrapped in the microparticles. Furthermore, the calculated loading content of $n$-eicosane when working with chloroform is quite the same as those obtained with $n$-hexadecane and ethyl acetate. Higher encapsulation efficiencies are obtained. 
Table 1. Thermal properties of $n$-hexadecane, neat poly(caprolactone) (PCL) microspheres and a series of $n$-hexadecane/PCL microcapsules obtained from ethyl acetate and chloroform solutions at three weight ratios between $n$-hexadecane and PCL.

\begin{tabular}{|c|c|c|c|c|c|c|c|c|c|c|c|c|c|}
\hline \multicolumn{2}{|c|}{ Sample Label } & \multicolumn{2}{|c|}{ Latent Heat $\left(\mathrm{J} \cdot \mathrm{g}^{-1}\right)$} & \multicolumn{2}{|c|}{$T_{\text {onset }}\left({ }^{\circ} \mathrm{C}\right)$} & \multicolumn{2}{|c|}{$T_{c}$ or $T_{m}\left({ }^{\circ} \mathrm{C}\right)$} & \multicolumn{2}{|c|}{$T_{\text {end }}\left({ }^{\circ} \mathrm{C}\right)$} & \multirow[t]{3}{*}{$L C(\%)$} & \multirow[t]{3}{*}{$E E(\%)$} & \multirow[t]{3}{*}{$X_{\mathrm{c}(\mathrm{th})}(\%)$} & \multirow[t]{3}{*}{$X_{\mathrm{c}(\mathrm{m})}(\%)$} \\
\hline \multirow{2}{*}{$n$-hexadecane } & heating & $199.4 \pm 2.2$ & & 17.9 & & 20.7 & & 23.7 & & & & & \\
\hline & cooling & $195.9 \pm 4.7$ & & 16.2 & & 16.0 & & 13.0 & & & & & \\
\hline \multirow{2}{*}{ PCL-EA } & heating & & $57.0 \pm 1.1$ & & 54.9 & & 56.4 & & 58.5 & & & & \\
\hline & cooling & & $54.7 \pm 1.3$ & & 41.2 & & 39.5 & & 37.2 & & & & \\
\hline \multirow{2}{*}{$\begin{array}{l}n \text {-hecxadecane } \\
/ \text { PCL(30/70)-EA }\end{array}$} & heating & $52.1 \pm 7.3$ & $32.5 \pm 1.5$ & 17.7 & 55.0 & 19.9 & 56.2 & 20.2 & 57.7 & $26.1 \pm 3.7$ & $87.1 \pm 12.2$ & $33.3 \pm 1.5$ & $31.5 \pm 1.5$ \\
\hline & cooling & $51.7 \pm 6.6$ & $33.6 \pm 3.9$ & 16.0 & 41.5 & 15.9 & 39.9 & 14.7 & 37.1 & & & & \\
\hline $\begin{array}{l}\text { n-hecxadecane } \\
\text { /PCL(50/50)-EA }\end{array}$ & heating & $88.7 \pm 4.1$ & $25.0 \pm 0.6$ & 17.6 & 55.0 & 19.2 & 56.2 & 21.2 & 57.8 & $44.5 \pm 2.0$ & $89.0 \pm 4.1$ & $35.8 \pm 0.8$ & $32.0 \pm 0.7$ \\
\hline \multirow{2}{*}{$\begin{array}{l}n \text {-hecxadecane } \\
/ \text { PCL(70/30)-EA }\end{array}$} & heating & $113.2 \pm 7.2$ & $24.1 \pm 1.1$ & 17.5 & 55.0 & 19.5 & 56.2 & 22.7 & 58.4 & $56.8 \pm 3.7$ & $81.1 \pm 5.2$ & $57.7 \pm 2.8$ & $40.0 \pm 1.9$ \\
\hline & cooling & $111.7 \pm 5.1$ & $25.9 \pm 1.8$ & 16.1 & 40.8 & 16.4 & 38.8 & 13.6 & 35.8 & & & & \\
\hline \multirow{2}{*}{ PCL-Chl } & heating & & $59.6 \pm 2.0$ & & 55.6 & & 57.6 & & 59.8 & & & & \\
\hline & cooling & & $57.2 \pm 1.9$ & & 41.5 & & 37.9 & & 34.4 & & & & \\
\hline$n$-hecxadecane & heating & $35.6 \pm 0.7$ & $31.6 \pm 1.6$ & 15.9 & 54.9 & 18.1 & 56.2 & 19.1 & 57.8 & $17.8 \pm 0.4$ & $59.4 \pm 1.2$ & $32.4 \pm 1.6$ & $27.6 \pm 1.4$ \\
\hline PCL(30/70)-Chl & cooling & $35.3 \pm 1.0$ & $33.2 \pm 1.6$ & 13.6 & 41.2 & 12.8 & 39.0 & 11.9 & 36.1 & & & & \\
\hline$n$-hecxadecane & heating & $72.4 \pm 0.6$ & $25.0 \pm 0.3$ & 17.2 & 55.0 & 19.2 & 56.3 & 21.0 & 58.0 & $36.3 \pm 0.3$ & $72.6 \pm 0.6$ & $35.8 \pm 0.4$ & $28.1 \pm 0.1$ \\
\hline n-hecxadecane & heating & $99.4 \pm 5.7$ & $17.0 \pm 1.5$ & 17.5 & 55.0 & 19.5 & 56.2 & 21.0 & 57.7 & $49.9 \pm 2.8$ & $71.2 \pm 4.1$ & $40.5 \pm 2.7$ & $24.2 \pm 2.2$ \\
\hline /PCL(70/30)-Chl & cooling & $96.9 \pm 4.7$ & $15.8 \pm 0.4$ & 15.7 & 41.0 & 15.5 & 38.8 & 13.8 & 35.6 & & & & \\
\hline
\end{tabular}


Table 2. Thermal properties of $n$-eicosane, neat PCL microspheres and a series of $n$-eicosane/PCL microcapsules obtained from ethyl acetate and chloroform solutions at three weight ratios between $n$-eicosane and PCL.

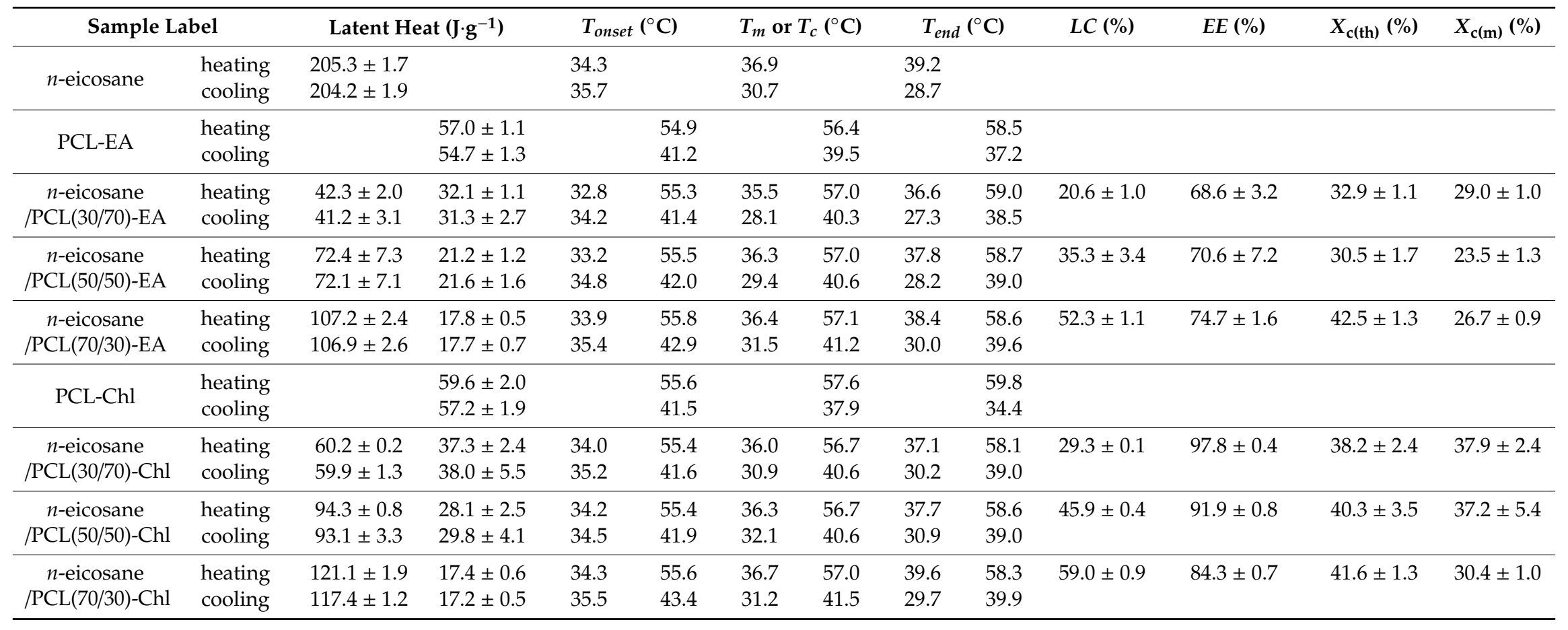


Differential Scanning Calorimetry was also used to determine the effect of solvent and core compounds on the thermal properties of PCL microparticles. All data were determined from the second run, and the first run was used to clear the thermal history. The DSC thermograms (Figures 4 and 5) show single melting peaks with maximum melting start and end temperatures of 54.9 and $56.4{ }^{\circ} \mathrm{C}$ for ethyl acetate solution, which increase slightly to 55.6 and $57.6^{\circ} \mathrm{C}$ for chloroform. The latent heat of fusion associated with these transitions is approximately 57.0 and $59.5 \mathrm{~J} \cdot \mathrm{g}^{-1}$, which corresponds to a crystallinity degree of $40.8 \%$ and $42.7 \%$, respectively. The presence of $n$-alkanes in the microparticles does not affect the melting temperatures of the PCL, but at high $n$-hexadecane content, there is a slight decrease in crystallization temperatures, while $n$-eicosane acts as a nucleating agent of the PCL, and therefore the crystallization temperatures increase. However, $n$-alkanes play a significant role in the formation of the crystalline phase of PCL. The increase in the $n$-alkane content leads to a decrease in the crystalline phase. This trend is quite similar, regardless of the solvent and $n$-alkane used.
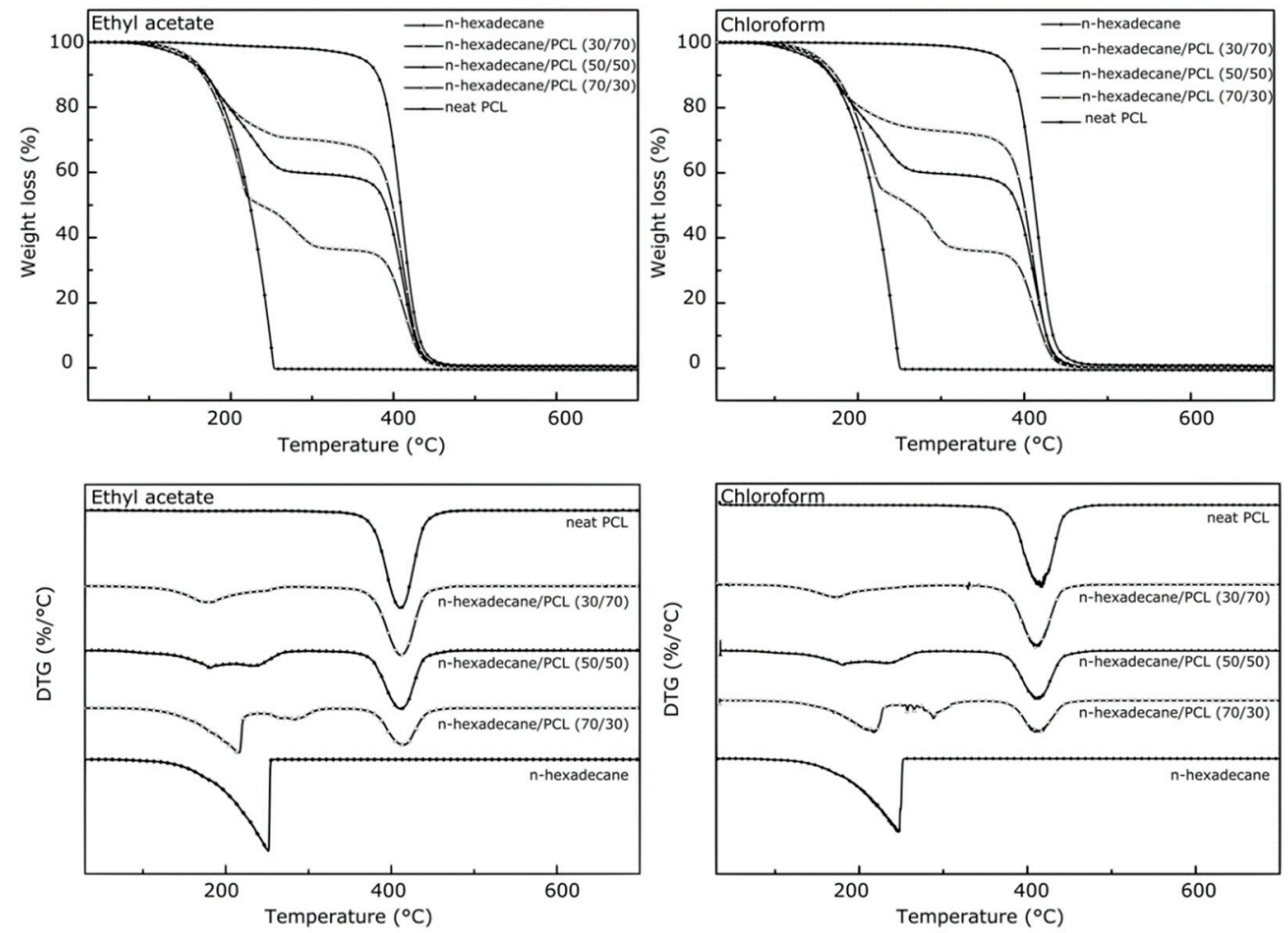

Figure 5. TG and DTG curves of $n$-hexadecane, neat PCL and the microencapsulated $n$-hexadecane.

In addition, the calculated crystallinity index of PCL in the MPCM is influenced by the solvent $/ n$-alkane pair used, which is correlated with the crystallization rate during the electrospraying process. When the measured crystallinity index values $\left(X_{P C L} \mathrm{~m}\right)$ are compared with the calculated (theoretical) values $\left(X_{P C L}\right.$ th), it can be seen that they are lower, except low weight ratio, where they are close. Thus, the presence of $n$-alkanes in the microparticles, and undoubtedly in the PCL matrix, reduces the PCL chain mobility, which gives rise to a lower crystallinity index in both the selected solvent and $n$-alkane systems.

Thus, the presence of $n$-alkanes leads to a decrease in the crystallinity index. In the early stages of the electrospray process, the droplets contain solvent, PCL macromolecular chains and PCM molecules. Depending on the solubility of PCM and PCL in each solvent system, the PCM molecules are dispersed together to form a mixed solution in which the macromolecular PCL chains have an intermolecular interaction or are entangled in the PCM chains when the solvent evaporates. The presence of PCM molecules reduces the mobility of PCL macromolecular chains and thus limits their availability for crystallization. This results in a more amorphous matrix [50-53]. In addition, the solvent used also 
affects the crystallinity index, PCL and $n$-alkanes are more soluble in Chl than in EA, which leads to the preparation of the most homogeneous working solutions.

The rapid evaporation rate of $\mathrm{Chl}$, during the early stages of the process, induces a higher phase separation between PCL and PCM, and therefore, a higher crystallinity index in the case of $n$-eicosane compared to the use of EA. The low evaporation rate of EA during the process leads to a higher degree of entanglement of the PCL macromolecular chains and PCM molecules, and therefore to a more amorphous matrix. Considering that $n$-hexadecane is liquid throughout the electro-spraying process, the molecules diffuse into the inner nucleus of the droplets during the slow evaporation of EA, allowing the PCL macromolecular chains to organize themselves to build the shell. On the other hand, the crystallinity index of PCL was found to decrease with increasing PCM content when Chl was used as a solvent. This observation suggests that the organization of the macromolecular chains is limited.

However, the difference between the theoretical content and the determined content of $n$-alkanes in the microparticles also suggests the presence of a PCM chain dispersed in the PCL matrix. Thus, the microparticles contain in the inner nucleus the $n$-alkanes, surrounded by a mixture of PCL/PCM chains, entrapped in a PCL shell.

\subsection{Thermal Stability of Electro-Sprayed mPCM}

The thermal stability of raw PCM, neat PCL electro-sprayed microparticles and MPCM were analyzed by TGA. TG and DTG curves of PCL microparticles, $n$-hexadecane (or $n$-eicosane) and $n$-hexadecane (or $n$-eicosane) based microparticles from chloroform and ethyl acetate are shown in Figure 5 (or Figure 6). The thermal behavior of $n$-hexadecane and $n$-eicosane displays single step degradation under $\mathrm{N}_{2}$ atmosphere. The decomposition of $n$-alkanes, characterized by the onset temperature at $5 \%$ weight loss, starts at 151.6 and $178.8{ }^{\circ} \mathrm{C}$ for $n$-hexadecane, and $n$-eicosane, respectively. The main decomposition peaks of $n$-hexadecane and $n$-eicosane corresponding to the $n$-alkanes backbone decomposition take place at 246 and 269, and the maximum rates of decomposition are about 2.2 , and $2.6 \%{ }^{\circ} \mathrm{C}^{-1}$, respectively. Furthermore, there is no residue for these compounds at over $280^{\circ} \mathrm{C}$. Under an inert atmosphere, PCL electro-sprayed microparticles display a single step degradation between 350 to $500^{\circ} \mathrm{C}$, corresponding to polymer pyrolysis with a maximum of degradation temperature at 411 or $413{ }^{\circ} \mathrm{C}$, according to the solvent used in the electrospraying process. The initial degradation temperatures $\left(T_{\text {onset }}\right.$ ) were found to occur at 359 and $369^{\circ} \mathrm{C}$ for samples prepared from ethyl acetate and chloroform, respectively. Furthermore, it seems that the solvent used has a few influences on the temperatures and maximum rate degradation (Table 3).

$\mathrm{N}$-alkanes based microparticles exhibit a two-step degradation. The first one, located from about 100 to $350{ }^{\circ} \mathrm{C}$ is ascribed to the PCM degradation, whereas the second one to the PCL matrix between 350 to $500{ }^{\circ} \mathrm{C}$. The presence of PCL does not have an effect on the initial degradation temperature in the case of $n$-hexadecane, but a shift from 10 to $18^{\circ} \mathrm{C}$ is observed for samples containing $n$-eicosane (Table 4). In the first degradation step, two types of phenomena occur, the first one corresponds to the degradation of $n$-alkane at the surface of the sample until $250{ }^{\circ} \mathrm{C}$. When the temperature reaches 60-62 ${ }^{\circ} \mathrm{C}$, PCL melts, and then all the microparticles samples are in a liquid state. Due to its lower density during the increase of temperature, a part of $n$-alkane chains can diffuse at the crucible surface and starts its degradation. The second phenomenon, between 250 to $300{ }^{\circ} \mathrm{C}$, is related to the entrapped $n$-alkane chains in the PCL matrix and their entanglements, which required more thermal energy to be degraded since PCL acts as a barrier to prevent the degradation. In addition, with the increasing of $n$-alkane content, the maximum degradation rate in the first stage increases gradually; on the other hand, the second step is similar to that of the PCL. 

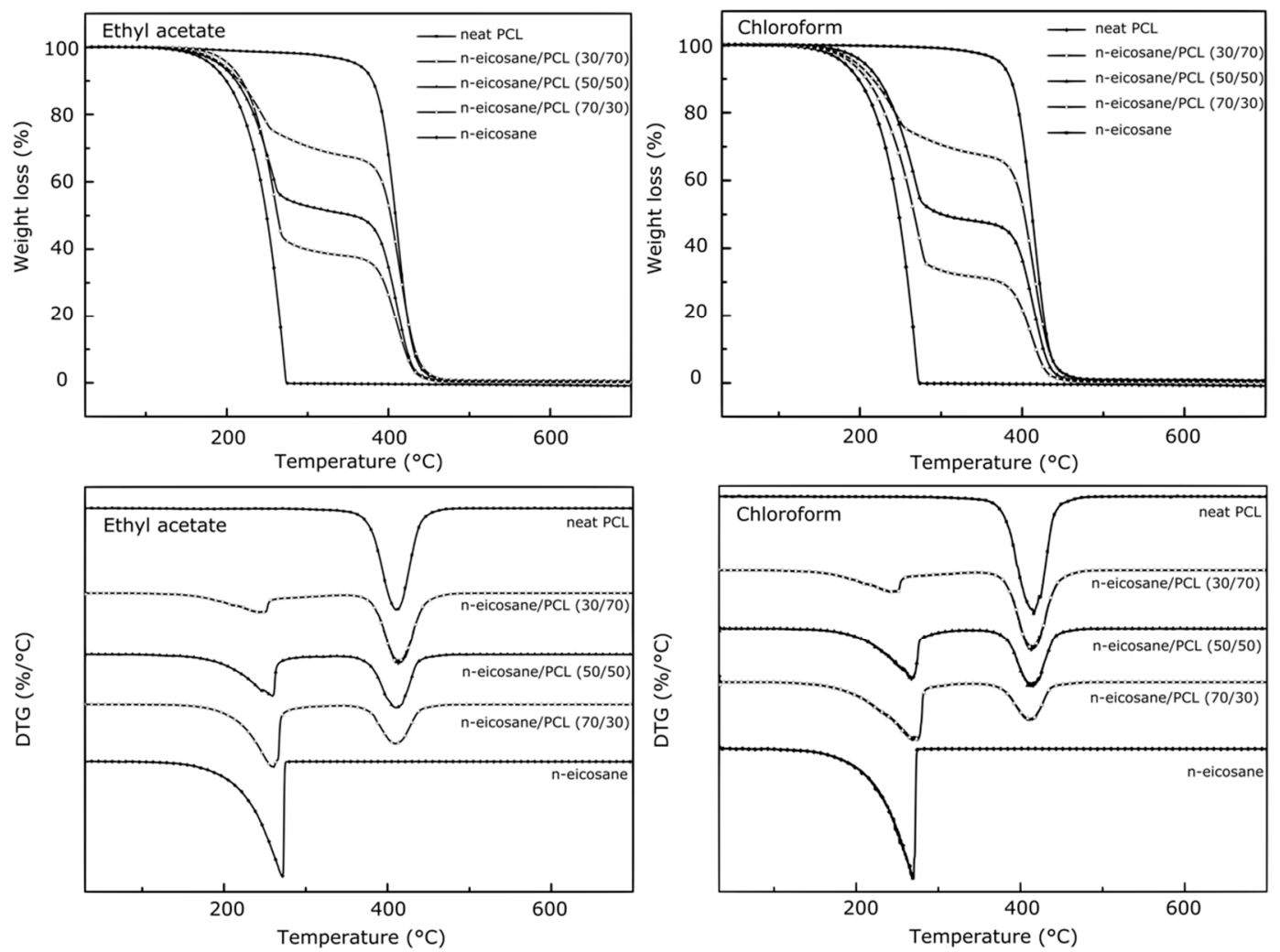

Figure 6. TG and DTG curves of $n$-eicosane, neat PCL and the microencapsulated $n$-eicosane.

On the one hand, even if the initial degradation temperatures are close to the $n$-hexadecane, the maximum degradation temperatures in the first stage are significantly lower than the raw compound, increase with the increase in the loading content, and are not very dependent on the solvent used. On the other hand, when $n$-eicosane was used as a core compound, the initial thermal degradation temperatures are 10 to $18{ }^{\circ} \mathrm{C}$ higher than that of the raw compound one and decrease with the increase in the loading content. The maximum degradation temperatures in the first stage are $30{ }^{\circ} \mathrm{C}$ lower than $n$-eicosane one for low loading content and increase up to the $n$-alkane one at higher loading content. Furthermore, chloroform based microparticles have better thermal stability than the ethyl acetate-based one. This stability is related to the affinity between PCL and $n$-alkanes chains in the solvent solutions, which can favorize the entanglement during the electro-spraying process. 
Table 3. Thermogravimetric data for of $n$-hexadecane, neat PCL microsphere and $n$-hexadecane microcapsules in inert atmosphere at a heating rate of $10{ }^{\circ} \mathrm{C} \cdot$ min ${ }^{-1}$.

\begin{tabular}{|c|c|c|c|c|c|c|c|}
\hline \multirow[b]{2}{*}{ Sample } & \multirow[b]{2}{*}{$\begin{array}{c}\text { Initial } \\
\text { Degradation } \\
\text { Temperature }\left({ }^{\circ} \mathrm{C}\right)\end{array}$} & \multicolumn{3}{|c|}{ First Step } & \multicolumn{3}{|c|}{ Second Step } \\
\hline & & $\begin{array}{c}\text { Weight Loss } \\
\left(100-350{ }^{\circ} \mathrm{C}\right)(\%)\end{array}$ & $\begin{array}{c}\text { Maximum } \\
\text { Degradation } \\
\text { Temperature }\left({ }^{\circ} \mathrm{C}\right)\end{array}$ & $\begin{array}{c}\text { Maximum } \\
\text { Degradation Rate } \\
\left(\% /{ }^{\circ} \mathrm{C}\right)\end{array}$ & $\begin{array}{l}\text { Weight Loss } \\
\left(350-500^{\circ} \mathrm{C}\right)(\%)\end{array}$ & $\begin{array}{c}\text { Maximum } \\
\text { Degradation } \\
\text { Temperature }\left({ }^{\circ} \mathrm{C}\right)\end{array}$ & $\begin{array}{c}\text { Maximum } \\
\text { Degradation Rate } \\
\left(\% .{ }^{\circ} \mathrm{C}^{-1}\right)\end{array}$ \\
\hline PCL-EA & $358.9 \pm 3.1$ & $4.2 \pm 0.9$ & - & - & $95.0 \pm 1.1$ & $411.4 \pm 0.4$ & $2.2 \pm 0.1$ \\
\hline PCL-Chl & $369.2 \pm 3.6$ & $3.0 \pm 0.4$ & - & - & $96.1 \pm 0.4$ & $413.4 \pm 1.6$ & $2.3 \pm 0.02$ \\
\hline Raw $n$-hexadecane & $151.6 \pm 1.1$ & $99.4 \pm 0.1$ & $246.6 \pm 0.7$ & $2.2 \pm 0.1$ & - & - & - \\
\hline $\begin{array}{c}n \text {-hexadecane/PCL } \\
\text { (30/70)-EA }\end{array}$ & $150.8 \pm 1.9$ & $29.6 \pm 1.7$ & $174.3 \pm 9.1$ & $0.3 \pm 0.1$ & $69.6 \pm 1.9$ & $412.9 \pm 3.4$ & $2.0 \pm 0.9$ \\
\hline $\begin{array}{l}n \text {-hexadecane/PCL } \\
\text { (50/50)-EA }\end{array}$ & $145.8 \pm 2.3$ & $39.5 \pm 5.7$ & $183.5 \pm 10.3$ & $0.5 \pm 0.2$ & $59.3 \pm 6.3$ & $411.9 \pm 2.4$ & $1.4 \pm 0.2$ \\
\hline $\begin{array}{c}n \text {-hexadecane/PCL } \\
\text { (70/30)-EA }\end{array}$ & $149.5 \pm 5.8$ & $59.2 \pm 4.3$ & $214.9 \pm 5.9$ & $0.9 \pm 0.2$ & $39.9 \pm 8.5$ & $413.3 \pm 1.4$ & $1.0 \pm 0.2$ \\
\hline $\begin{array}{l}n \text {-hexadecane/PCL } \\
\text { (30/70)-Chl }\end{array}$ & $150.1 \pm 3.1$ & $27.3 \pm 0.9$ & $173.5 \pm 2.7$ & $0.3 \pm 0.03$ & $72.0 \pm 1.0$ & $413.7 \pm 0.3$ & $1.8 \pm 0.02$ \\
\hline $\begin{array}{l}n \text {-hexadecane/PCL } \\
\text { (50/50)-Chl }\end{array}$ & $147.3 \pm 4.6$ & $37.4 \pm 2.4$ & $177.5 \pm 1.6$ & $0.4 \pm 0.04$ & $61.8 \pm 2.8$ & $412.5 \pm 1.5$ & $1.5 \pm 0.1$ \\
\hline $\begin{array}{l}n \text {-hexadecane/PCL } \\
\text { (70/30)-Chl }\end{array}$ & $151.8 \pm 6.1$ & $60.4 \pm 4.0$ & $217.0 \pm 1.0$ & $0.9 \pm 0.1$ & $38.9 \pm 7.3$ & $414.7 \pm 2.4$ & $0.9 \pm 0.1$ \\
\hline
\end{tabular}


Table 4. Thermogravimetric data for of $n$-eicosanee, neat PCL microsphere and $n$-eicosane microcapsules in inert atmosphere at a heating rate of $10{ }^{\circ} \mathrm{C} \cdot \mathrm{min}{ }^{-1}$

\begin{tabular}{|c|c|c|c|c|c|c|c|}
\hline \multirow[b]{2}{*}{ Sample } & \multirow[b]{2}{*}{$\begin{array}{c}\text { Initial } \\
\text { Degradation } \\
\text { Temperature }\left({ }^{\circ} \mathrm{C}\right)\end{array}$} & \multicolumn{3}{|c|}{ First Step } & \multicolumn{3}{|c|}{ Second Step } \\
\hline & & $\begin{array}{c}\text { Weight Loss } \\
\left(100-350{ }^{\circ} \mathrm{C}\right)(\%)\end{array}$ & $\begin{array}{c}\text { Maximum } \\
\text { Degradation } \\
\text { Temperature }\left({ }^{\circ} \mathrm{C}\right)\end{array}$ & $\begin{array}{c}\text { Maximum } \\
\text { Degradation Rate } \\
\left(\% /{ }^{\circ} \mathrm{C}\right)\end{array}$ & $\begin{array}{c}\text { Weight Loss } \\
\left(350-500^{\circ} \mathrm{C}\right)(\%)\end{array}$ & $\begin{array}{c}\text { Maximum } \\
\text { Degradation } \\
\text { Temperature }\left({ }^{\circ} \mathrm{C}\right)\end{array}$ & $\begin{array}{c}\text { Maximum } \\
\text { Degradation Rate } \\
\left(\% /{ }^{\circ} \mathrm{C}\right)\end{array}$ \\
\hline PCL-EA & $358.9 \pm 3.1$ & $4.2 \pm 0.9$ & - & - & $95.0 \pm 1.1$ & $411.4 \pm 0.4$ & $2.2 \pm 0.1$ \\
\hline PCL-Chl & $369.2 \pm 3.6$ & $3.0 \pm 0.4$ & - & - & $96.1 \pm 0.4$ & $413.4 \pm 1.6$ & $2.3 \pm 0.02$ \\
\hline raw $n$-eicosane & $178.8 \pm 1.3$ & $99.9 \pm 0.1$ & $269.1 \pm 0.01$ & $2.6 \pm 0.1$ & - & - & - \\
\hline $\begin{array}{c}\text { n-eicosane/PCL } \\
\text { (30/70)-EA }\end{array}$ & $196.4 \pm 9.7$ & $26.9 \pm 3.0$ & $236.1 \pm 6.1$ & $0.4 \pm 0.1$ & $72.4 \pm 5.4$ & $414.9 \pm 0.6$ & $1.7 \pm 0.1$ \\
\hline $\begin{array}{c}n \text {-eicosane/PCL } \\
\text { (50/50)-EA }\end{array}$ & $194.0 \pm 13.6$ & $44.1 \pm 4.9$ & $254.8 \pm 3.5$ & $0.9 \pm 0.04$ & $55.3 \pm 5.4$ & $413.6 \pm 2.3$ & $1.3 \pm 0.2$ \\
\hline $\begin{array}{c}n \text {-eicosane/PCL } \\
\text { (70/30)-EA }\end{array}$ & $188.8 \pm 14.0$ & $58.1 \pm 6.8$ & $248.2 \pm 12.9$ & $1.2 \pm 0.2$ & $41.6 \pm 6.8$ & $407.0 \pm 5.1$ & $1.0 \pm 0.3$ \\
\hline $\begin{array}{c}\text { n-eicosane/PCL } \\
\text { (30/70)-Chl }\end{array}$ & $194.3 \pm 11.8$ & $30.6 \pm 4.4$ & $237.3 \pm 4.9$ & $0.4 \pm 0.1$ & $68.8 \pm 4.3$ & $414.4 \pm 1.8$ & $1.6 \pm 0.1$ \\
\hline $\begin{array}{l}\text { n-eicosane/PCL } \\
\text { (50/50)-Chl }\end{array}$ & $195.9 \pm 7.8$ & $49.5 \pm 4.0$ & $268.1 \pm 1.0$ & $1.0 \pm 0.1$ & $49.8 \pm 3.7$ & $414.1 \pm 2.2$ & $1.2 \pm 0.1$ \\
\hline $\begin{array}{c}\text { n-eicosane/PCL } \\
\text { (70/30)-Chl }\end{array}$ & $186.8 \pm 10.5$ & $69.3 \pm 1.1$ & $269.5 \pm 5.6$ & $1.3 \pm 0.2$ & $30.2 \pm 0.8$ & $413.2 \pm 3.5$ & $0.7 \pm 0.04$ \\
\hline
\end{tabular}




\subsection{Structural Stability of the Electro-Sprayed $m P C M$}

The shape stabilization of the electro-sprayed microparticles shape was investigated by SEM analyses after the heating and cooling process from -30 to $50{ }^{\circ} \mathrm{C}$ and 50 to $-30{ }^{\circ} \mathrm{C}$ (Figure 7). After the thermal treatment, the shape and the particle morphology present any changes. The observed particles are spherical shape, smooth, and compact surface morphology. The absence of $n$-hexadecane on the SEM micrographs indicated that the PCL shell protects the PCM core from the leakage. Therefore the entrapment of PCM in the PCL matrix with this electrospraying process allows obtaining suitable stability.
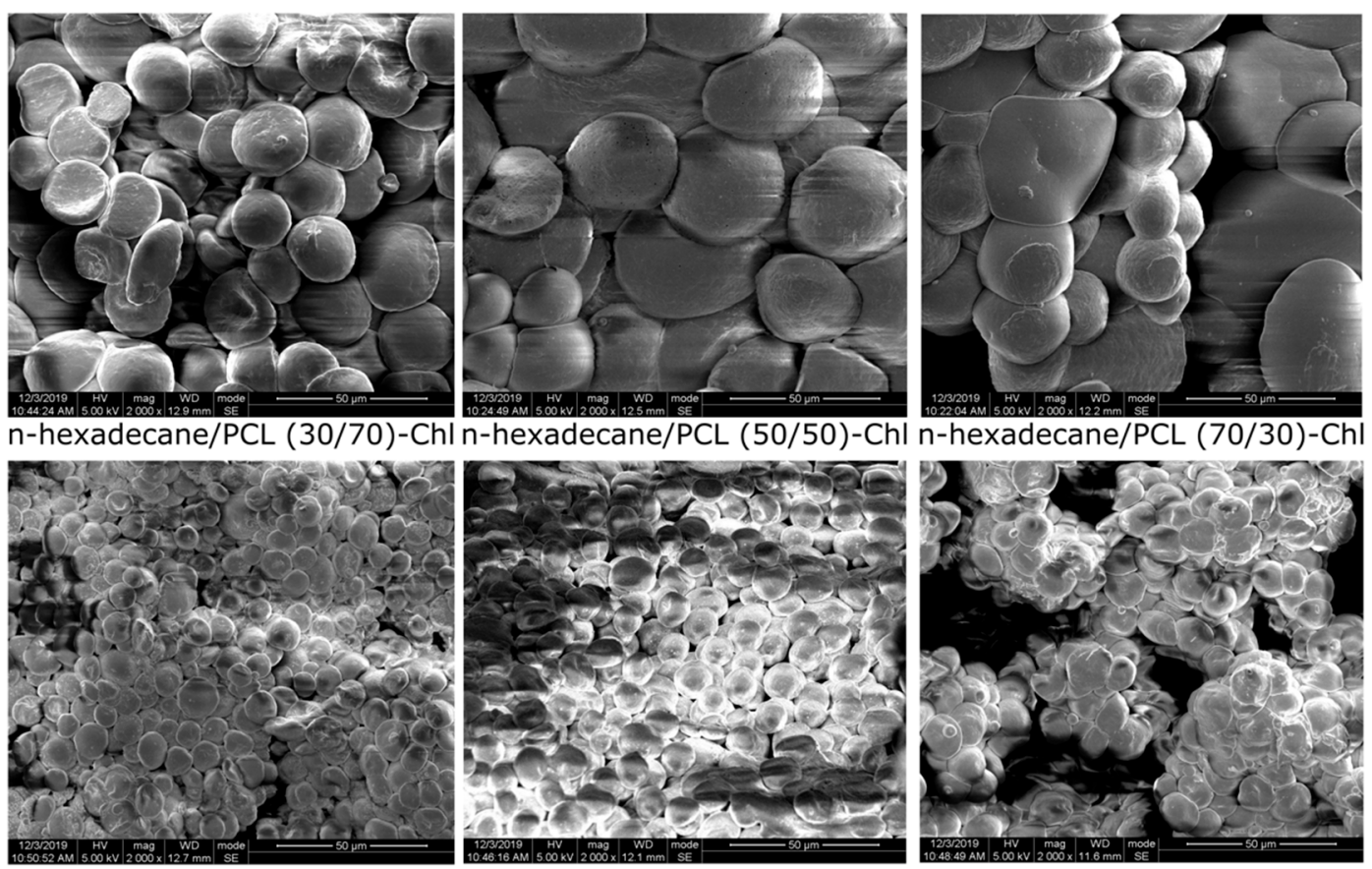

n-hexadecane/PCL (30/70)-EA

n-hexadecane/PCL (50/50)-EA

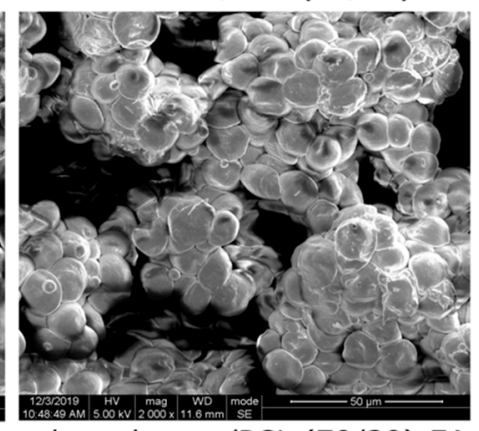

Figure 7. SEM micrographs of $n$-hexadecane/PCL microparticles after thermal treatment.

\section{Conclusions}

The microencapsulated phase change materials in the PCL matrix were successfully manufactured by an electrospray process, using two types of solvents, ethyl acetate and chloroform, and three loading contents ( $30 \%, 50 \%$, and $70 \%$ by weight). The process not only produces particles with a mono-dispersed particle size distribution, an average micrometric diameter, a non-porous morphology, but also a high encapsulation efficiency. The microparticles have a latent heat correlated to the theoretical load and good thermal stability. The break up process in the early stages of the electroplating method mainly determines the particle size of the MPCM. Thus, depending on the choice of $n$-alkane, $n$-hexadecane, or n-eicosane, two phenomena occur. On the one hand, in the case of $n$-hexadecane, which is in a liquid state at room temperature, the break-up of the charged droplets takes place throughout the flight process, from the nozzle to the collector, which allows the solvent to evaporate entirely and thus obtain a low mean diameter. On the other hand, the droplets loaded with $n$-eicosane break-up only in the earliest stages of the flight process, as the evaporation of the solvent leads to the $n$-alkane crystallization, which stops the process, resulting in higher mean diameters and broad size distribution. The surface morphology of the electro-sprayed $\mathrm{mPCM}$ is either smooth, and dense or rough and wrinkled when $n$-hexadecane, and $n$-eicosane are used, respectively. Besides, $n$-eicosane tends to be on the surface of particles as its loading content increases. Also, the choice of solvent affects the particle size and morphology of the particles, which may be related to changes in the physico-chemical properties of solutions, such as surface tension, vapor pressure, and viscosity. The loading content depends 
mainly on the diffusion of $n$-alkane chains during the process, which is also influenced by solvent evaporation or phase separation, the interactions between PCL macromolecular chains, and $n$-alkane chains, and the evolution of the physical state of PCM. Thus, the encapsulation efficiency and charge content of an $n$-alkane liquid at room temperature are respectively higher and lower than those of a solid $n$-alkane in ethyl acetate, but in chloroform, it is the opposite.

Author Contributions: Conceptualization, S.Z. and F.S.; methodology, S.Z., C.C. and F.S.; validation, C.C. and F.S.; formal analysis, S.Z. and F.S.; writing — original draft preparation, S.Z.; writing — review and editing, F.S.; supervision, C.C. and F.S. All authors have read and agreed to the published version of the manuscript.

Funding: This research received no external funding.

Acknowledgments: The authors are very grateful to Sichuan University (Chengdu, China) for microscopy analyses (SEM) and the technical and financial support from GEMTEX laboratory (Lille, France). The author Shengchang Zhang is also thankful for the financial support for a PhD from the China Scholarship Council (CSC).

Conflicts of Interest: The authors declare no conflict of interest.

\section{References}

1. Sharma, A.; Tyagi, V.V.; Chen, C.R.; Buddhi, D. Review on thermal energy storage with phase change materials and applications. Renew. Sustain. Energy Rev. 2009, 13, 318-345. [CrossRef]

2. Zalba, B.; Marín, J.M.; Cabeza, L.F.; Mehling, H. Review on thermal energy storage with phase change: Materials, heat transfer analysis and applications. Appl. Therm. Eng. 2003, 23, 251-283. [CrossRef]

3. Shchukina, E.M.; Graham, M.; Zheng, Z.; Shchukin, D.G. Nanoencapsulation of phase change materials for advanced thermal energy storage systems. Chem. Soc. Rev. 2018, 47, 4156-4175. [CrossRef] [PubMed]

4. Zhang, N.; Yuan, Y.; Cao, X.; Du, Y.; Zhang, Z.; Gui, Y. Latent Heat Thermal Energy Storage Systems with Solid-Liquid Phase Change Materials: A Review. Adv. Eng. Mater. 2018, 20, 1700753. [CrossRef]

5. Salaün, F. The Manufacture of Microencapsulated Thermal Energy Storage Compounds Suitable for Smart Textile. In Developments in Heat Transfer; Dos Santos Bernardes, M.A., Ed.; Intech: Rijeka, Croatia, 2011; pp. 171-198. [CrossRef]

6. Mondal, S. Phase change materials for smart textiles-An overview. Appl. Therm. Eng. 2008, 28, 1536-1550. [CrossRef]

7. Sarier, N.; Onder, E. Organic phase change materials and their textile applications: An overview. Thermochim. Acta 2012, 540, 7-60. [CrossRef]

8. Hallaj, S.A.; Selman, J.R. A Novel Thermal Management System for Electric Vehicle Batteries Using Phase-Change Material. J. Electrochem. Soc. 2000, 147, 3231-3236. [CrossRef]

9. Liu, Z.; Yu, Z.; Yang, T.; Qin, D.; Li, S.; Zhang, G.; Haghighat, F.; Joybari, M.M. A review on macro-encapsulated phase change material for building envelope applications. Build. Environ. 2018, 144, 281-294. [CrossRef]

10. Wang, T.; Jiang, Y.; Huang, J.; Wang, S. High thermal conductive paraffin/calcium carbonate phase change microcapsules based composites with different carbon network. Appl. Energy 2018, 218, 184-191. [CrossRef]

11. Liu, L.; Alva, G.; Huang, X.; Fang, G. Preparation, heat transfer and flow properties of microencapsulated phase change materials for thermal energy storage. Renew. Sustain. Energy Rev. 2016, 66, 399-414. [CrossRef]

12. Pan, L.; Tao, Q.; Zhang, S.; Wang, S.; Zhang, J.; Wang, S.; Wang, Z.; Zhang, Z. Preparation, characterization and thermal properties of micro-encapsulated phase change materials. Sol. Energy Mater. Sol. Cells 2012, 98, 66-70. [CrossRef]

13. Bayés-García, L.; Ventolà, L.; Cordobilla, R.; Benages, R.; Calvet, T.; Cuevas-Diarte, M.A. Phase Change Materials (PCM) microcapsules with different shell compositions: Preparation, characterization and thermal stability. Sol. Energy Mater. Sol. Cells 2010, 94, 1235-1240. [CrossRef]

14. Alkan, C.; Sarı, A.; Karaipekli, A. Preparation, thermal properties and thermal reliability of microencapsulated n-eicosane as novel phase change material for thermal energy storage. Energy Convers. Manag. 2011, 52, 687-692. [CrossRef]

15. Salaün, F.; Devaux, E.; Bourbigot, S.; Rumeau, P. Development of Phase Change Materials in Clothing Part I: Formulation of Microencapsulated Phase Change. Text. Res. J. 2010, 80, 195-205. [CrossRef]

16. Salaün, F.; Devaux, E.; Bourbigot, S.; Rumeau, P. Thermoregulating response of cotton fabric containing microencapsulated phase change materials. Thermochim. Acta 2010, 506, 82-93. [CrossRef] 
17. Umair, M.M.; Zhang, Y.; Iqbal, K.; Zhang, S.; Tang, B. Novel strategies and supporting materials applied to shape-stabilize organic phase change materials for thermal energy storage-A review. Appl. Energy 2019, 235, 846-873. [CrossRef]

18. Salaün, F.; Devaux, E.; Bourbigot, S.; Rumeau, P. Influence of process parameters on microcapsules loaded with n-hexadecane prepared by in situ polymerization. Chem. Eng. J. 2009, 155, 457-465. [CrossRef]

19. Fredi, G.; Dorigato, A.; Fambri, L.; Pegoretti, A. Wax Confinement with Carbon Nanotubes for Phase Changing Epoxy Blends. Polymers 2017, 9, 405. [CrossRef]

20. Salaün, F.; Bedek, G.; Devaux, E.; Dupont, D.; Gengembre, L. Microencapsulation of a cooling agent by interfacial polymerization: Influence of the parameters of encapsulation on poly(urethane-urea) microparticles characteristics. J. Membr. Sci. 2011, 370, 23-33. [CrossRef]

21. Liu, X.; Lou, Y. Preparation of microencapsulated phase change materials by the sol-gel process and its application on textiles. Fibres Text. East. Eur. 2015, 23, 63-67.

22. Fredi, G.; Dire, S.; Callone, E.; Ceccato, R.; Mondadori, F.; Pegoretti, A. Docosane-Organosilica Microcapsules for Structural Composites with Thermal Energy Storage/Release Capability. Materials 2019, $12,1286$. [CrossRef] [PubMed]

23. Roy, J.C.; Ferri, A.; Giraud, S.; Jinping, G.; Salaün, F. Chitosan-carboxymethylcellulose-based polyelectrolyte complexation and microcapsule shell formulation. Int. J. Mol. Sci. 2018, 19, 2521. [CrossRef] [PubMed]

24. Roy, J.C.; Salaün, F.; Giraud, S.; Ferri, A.; Guan, J. Surface behavior and bulk properties of aqueous chitosan and type-B gelatin solutions for effective emulsion formulation. Carbohydr. Polym. 2017, 173, $202-214$. [CrossRef] [PubMed]

25. Sánchez-Silva, L.; Rodríguez, J.F.; Carmona, M.; Romero, A.; Sánchez, P. Thermal and morphological stability of polystyrene microcapsules containing phase-change materials. J. Appl. Polym. Sci. 2011, 120, 291-297. [CrossRef]

26. Alkan, C.; Aksoy, S.A.; Anayurt, R.A. Synthesis of poly (methyl methacrylate-co-acrylic acid)/n-eicosane microcapsules for thermal comfort in textiles. Text. Res. J. 2015, 85, 2051-2058. [CrossRef]

27. Su, W.; Darkwa, J.; Kokogiannakis, G. Review of solid-liquid phase change materials and their encapsulation technologies. Renew. Sustain. Energy Rev. 2015, 48, 373-391. [CrossRef]

28. Jamekhorshid, A.; Sadrameli, S.M.; Farid, M. A Review of microencapsulation methods of phase change materials (PCMs) as a thermal energy storage (TES) medium. Renew. Sustain. Energy Rev. 2014, 31, 531-542. [CrossRef]

29. Salaün, F. Microencapsulation technology for smart textile coatings. In Active Coatings for Smart Textiles; Hu, J., Ed.; Woodhead Publishing: Duxford, UK, 2016; pp. 179-220. [CrossRef]

30. Zhang, S.C.; Campagne, C.; Salaun, F. Influence of Solvent Selection in the Electrospraying Process of Polycaprolactone. Appl. Sci. 2019, 9, 402. [CrossRef]

31. Jaworek, A. Micro-and nanoparticle production by electrospraying. Powder Technol. 2007, 176, 18-35. [CrossRef]

32. Jain, R.A. The manufacturing techniques of various drug loaded biodegradable poly(lactide-co-glycolide) (PLGA) devices. Biomaterials 2000, 21, 2475-2490. [CrossRef]

33. Bock, N.; Dargaville, T.R.; Woodruff, M.A. Electrospraying of polymers with therapeutic molecules: State of the art. Prog. Polym. Sci. 2012, 37, 1510-1551. [CrossRef]

34. Fukui, Y.; Maruyama, T.; Iwamatsu, Y.; Fujii, A.; Tanaka, T.; Ohmukai, Y.; Matsuyama, H. Preparation of monodispersed polyelectrolyte microcapsules with high encapsulation efficiency by an electrospray technique. Colloids Surf. Physicochem. Eng. Asp. 2010, 370, 28-34. [CrossRef]

35. Bock, N.; Woodruff, M.A.; Hutmacher, D.W.; Dargaville, T.R. Electrospraying, a Reproducible Method for Production of Polymeric Microspheres for Biomedical Applications. Polymers 2011, 3, 131-149. [CrossRef]

36. Chen, C.; Wang, L.; Huang, Y. Electrospun phase change fibers based on polyethylene glycol/cellulose acetate blends. Appl. Energy 2011, 88, 3133-3139. [CrossRef]

37. McCann, J.T.; Marquez, M.; Xia, Y. Melt coaxial electrospinning: A versatile method for the encapsulation of solid materials and fabrication of phase change nanofibers. Nano Lett. 2006, 6, 2868-2872. [CrossRef] [PubMed] 
38. Cai, Y.; Ke, H.; Dong, J.; Wei, Q.; Lin, J.; Zhao, Y.; Song, L.; Hu, Y.; Huang, F.; Gao, W.; et al. Effects of nano-SiO 2 on morphology, thermal energy storage, thermal stability, and combustion properties of electrospun lauric acid/PET ultrafine composite fibers as form-stable phase change materials. Appl. Energy 2011, 88, 2106-2112. [CrossRef]

39. Moghaddam, M.K.; Mortazavi, S.M.; Khayamian, T. Preparation of calcium alginate microcapsules containing n-nonadecane by a melt coaxial electrospray method. J. Electrost. 2015, 73, 56-64. [CrossRef]

40. Moghaddam, M.K.; Mortazavi, S.M.; Khaymian, T. Micro/nano-encapsulation of a phase change material by coaxial electrospray method. Iran. Polym. J. 2015, 24, 759-774. [CrossRef]

41. Kamali Moghaddam, M.; Mortazavi, S.M. Preparation, characterisation and thermal properties of calcium alginate/n-nonadecane microcapsules fabricated by electro-coextrusion for thermo-regulating textiles. J. Microencapsul. 2015, 32, 737-744. [CrossRef]

42. Yuan, W.-J.; Wang, Y.-P.; Li, W.; Wang, J.-P.; Zhang, X.-X.; Zhang, Y.-K. Microencapsulation and characterization of polyamic acid microcapsules containing n-octadecane via electrospraying method. Mater. Express 2015, 5, 480-488. [CrossRef]

43. Roy, J.C.; Giraud, S.; Ferri, A.; Mossotti, R.; Guan, J.; Salaun, F. Influence of process parameters on microcapsule formation from chitosan-Type B gelatin complex coacervates. Carbohydr. Polym. 2018, 198, 281-293. [CrossRef] [PubMed]

44. Choi, E.-J.; Kim, C.-H.; Park, J.-K. Structure-property relationship in PCL/starch blend compatibilized with starch-g-PCL copolymer. J. Polym. Sci. Part B Polym. Phys. 1999, 37, 2430-2438. [CrossRef]

45. Zhang, S.; Campagne, C.; Salaün, F. Preparation of Electrosprayed Poly(caprolactone) Microparticles Based on Green Solvents and Related Investigations on the Effects of Solution Properties as Well as Operating Parameters. Coatings 2019, 9, 84. [CrossRef]

46. Xie, J.; Marijnissen, J.C.; Wang, C.H. Microparticles developed by electrohydrodynamic atomization for the local delivery of anticancer drug to treat C6 glioma in vitro. Biomaterials 2006, 27, 3321-3332. [CrossRef]

47. Entekhabi, E.; Haghbin Nazarpak, M.; Moztarzadeh, F.; Sadeghi, A. Design and manufacture of neural tissue engineering scaffolds using hyaluronic acid and polycaprolactone nanofibers with controlled porosity. Mater. Sci. Eng. C 2016, 69, 380-387. [CrossRef]

48. Bordes, C.; Freville, V.; Ruffin, E.; Marote, P.; Gauvrit, J.Y.; Briancon, S.; Lanteri, P. Determination of poly(epsilon-caprolactone) solubility parameters: Application to solvent substitution in a microencapsulation process. Int. J. Pharm. 2010, 383, 236-243. [CrossRef]

49. Pereira, C.N.; Vebber, G.C. A Relationship Between the Heat of Vaporization, Surface Tension, and the Solubility Parameters, Which Includes the Ratio of the Coordination Numbers, Based on Stefan's Rule. Polym. Eng. Sci. 2018, 59, 312-321. [CrossRef]

50. Valo, H.; Peltonen, L.; Vehvilainen, S.; Karjalainen, M.; Kostiainen, R.; Laaksonen, T.; Hirvonen, J. Electrospray encapsulation of hydrophilic and hydrophobic drugs in poly(L-lactic acid) nanoparticles. Small 2009, 5, 1791-1798. [CrossRef]

51. Mochane, M.J.; Luyt, A.S. Preparation and properties of polystyrene encapsulated paraffin wax as possible phase change material in a polypropylene matrix. Thermochim. Acta 2012, 544, 63-70. [CrossRef]

52. Jenquin, M.R.; McGinity, J.W. Characterization of acrylic resin matrix films and mechanisms of drug-polymer interactions. Int. J. Pharm. 1994, 101, 23-34. [CrossRef]

53. Dubernet, C. Thermoanalysis of microspheres. Thermochim. Acta 1995, 248, 259-269. [CrossRef]

(C) 2020 by the authors. Licensee MDPI, Basel, Switzerland. This article is an open access article distributed under the terms and conditions of the Creative Commons Attribution (CC BY) license (http://creativecommons.org/licenses/by/4.0/). 